near-plausible to the inexcusably fantastic. The book as a whole should be an antidote to the general hostility with which The X-Files has been greeted by the PUS community, who condemn it as pandering to the public taste for pseudoscience. When Chris Carter was invited to address the Committee for Scientific Investigation into Claims of the Paranormal (CSICOP), he felt that his audience held him personally responsible for "all the loopy, looney trends in angels and aliens, in superstition, and even in fundamentalism". It was as if he was "threatening to destroy yet another generation of minds by feeding them more bogus claptrap". But Carter had his secret weapon in Anne Simon, who, like Carter's accusers, "is a skeptic and, like Agent Scully, has a trust and faith in the scientific process". CSICOP seems to have got the message - "I've never heard from them since," says Carter.

Henry Gee is a senior editor at Nature.

\section{Simplicity out of complexity}

\section{Strange Beauty: Murray Gell-Mann and the Revolution in Twentieth- \\ Century Physics \\ by George Johnson \\ Knopf/Cape: 1999/2000. 432 pp. \$30/£17.99 \\ Jonathan R. Ellis}

Murray Gell-Mann is one of the towering figures in the field that uncovered a deeper and simpler layer of matter. George Johnson skilfully describes the fascinating train of events that led to the postulation and discovery of quarks, reconstructing the story around Gell-Mann's central role, and counterpointing it with many insights into GellMann's complex personality.

Gell-Mann's family background and childhood give us intriguing insights into his personality. His immigrant parents' fortunes fluctuated; his father was apparently a hard taskmaster and his mother neurotic. Here we learn the true origin of the hyphen in his family name. Gell-Mann's legendary polymath and polyglot precocity shone forth early. He skipped three years of school, and his remarkable high-school valedictorian address was featured in a cartoon in The New Yorker. He sped charmingly through undergraduate school at Yale and graduate school at MIT, bursting onto the particle-physics scene at the ripe old age of 21 .

For most of the next two decades, GellMann dominated the international world of high-energy physics. He played a leading role in the discovery of the strangeness quantum number, SU(3) symmetry and the eightfold way, quarks and current algebra not to mention dispersion relations, $\mathrm{V}-\mathrm{A}$

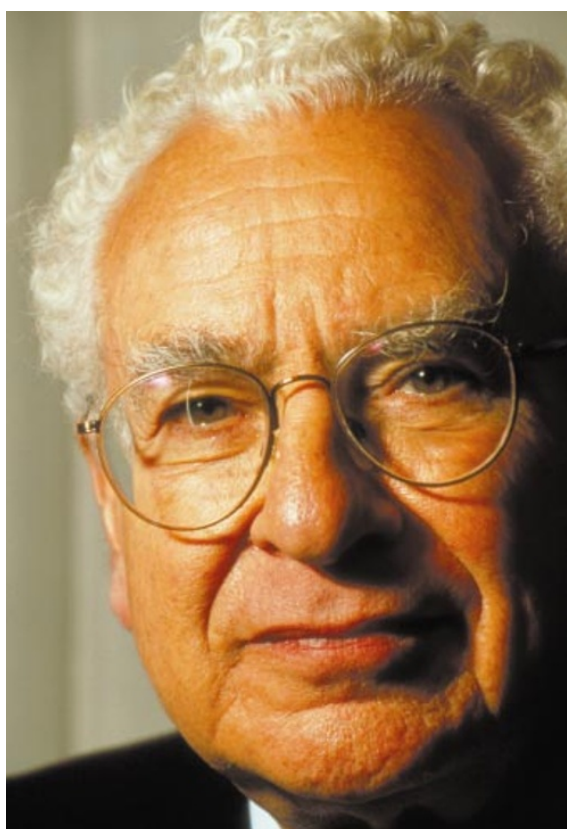

Polymath and polyglot: Gell-Mann dominated the world of high-energy physics for 20 years.

theory, and much more. During this period, he worked very closely with experimental physicists, providing them with crucial guidance and helping to resolve the apparently conflicting results they sometimes obtained. Gell-Mann brought to all this both his light side of personal charm and his dark side of combativity. It culminated in his triumphal acceptance of the "Swedish prize"; his speech was made partly in the local lingo.

My own first encounters with Murray happened around this time, when I was a student - brilliant and inspiring lectures that cemented my ambition to attempt research in particle physics, the trickle-down of his deep insights into quarks and gluons via Bruno Renner, his collaborator and my advisor, and being charmed and flattered by the great man at our first personal meeting in a motel on the South Dixie Highway in Coral Gables. A year or two later, I made my postdoctoral pilgrimage to the Caltech ashram, but failed to hit it off with the guru. He was always surrounded by sufficient disciples, but by this time, field theorists were starting to have their revenge.

Gell-Mann's attitude towards field theory had always been ambivalent, as he regarded it as a disposable means to an S-matrix end. He did not surf the gauge-theory wave as dominatingly as the symmetric waves of yore, as Johnson explains in his account of Gell-Mann's contribution to the birth of quantum chromodynamics. Here, by the way, the author takes one of his few scientific mis-steps: he wrongly identifies flavour SU(3) with colour SU(3). Also, he underestimates the extent to which the latter had been generally expected; and the importance of chiral symmetry in identifying gluons as vector particles could have been underlined.

Gell-Mann continued to produce influential ideas for a while yet - for example, his co-discovery of the see-saw mechanism for light-neutrino masses in the context of grand unified theories, which is now so topical (although not mentioned by Johnson).

Murray's subsequent forays into supergravity, superstrings and cosmology had less impact, but I am not competent to assess his later contributions to complexity theory.

Johnson tells us much about Gell-Mann's foibles of character, including his penchant for learning languages and demonstrating this prowess, his encyclopaedic knowledge and inability to resist displaying it, and his sardonic wit. The complex relationship between Gell-Mann and his Caltech colleague Richard Feynman is less clear. It contained strong elements of rivalry, but also friendship and respect, shading into insecurity. A comparison of this book with Genius (Little, Brown, 1994), James Gleick's biography of Feynman, inevitably comes to mind. Strange Beauty is certainly equally easy and interesting to read, and also quite thoroughly researched. Genius is perhaps stronger on psychological insight, and Strange Beauty may be stronger on scientific history. But these are details; anyone who enjoyed Genius will surely also appreciate Strange Beauty. The degree of appreciation may depend on the reader's degree of empathy with GellMann's character.

Personally, I have fond memories of Murray - such as jostling to cede each other precedence on leaving a men's room at Caltech (Murray won, of course) - and tremendous respect for his scientific achievements. As this book reveals, his personality is complex, and this may ultimately have restricted his scientific stature. He had a continual struggle with writer's block, and his attention often wandered far from physics. If he had not put so much energy into knowing everything about everything, travelling everywhere, seeing every bird, consulting left and right, eating gourmet food, and other distractions, might he have achieved even more, getting up there with the greats of the millennium, not just of the century? His personal life might have been less interesting, but Gell-Mann might finally have been more satisfied. Setting aside these night thoughts, in this book you have a faithful record of one of the giants of late-twentieth-century physics - his life as well as his memorable science. This is a riveting read for anybody interested in the history and sociology of late-twentiethcentury science.

Jonathan R. Ellis is in the Theoretical

Physics Division, European Laboratory for

Particle Physics, CERN, CH-1211 Geneva 23, Switzerland. 